\title{
LA CASA DE CONTRATACIÓN DE ORÁN Y EL CAMBIO EN LA FILOSOFÍA DE LAS TRANSACCIONES ENTRE BERBERÍA Y VALENCIA, 1510-1514
}

Por

ANDRÉS DÍAZ BORRÁS

CSIC, Barcelona

Las relaciones entre Valencia y Berbería habían atravesado vicisitudes muy cambiantes a lo largo de la Edad Media. No obstante, se fue configurando una estructura de relaciones en una doble vertiente. Por un lado, los negocios de las transacciones constituyeron a lo largo del siglo XIV y buena parte del XV una faceta importantísima para la vitalidad financiera urbana, por otro lado, se generará toda una dinámica de enfrentamiento y tensiones que, en ascenso, irá reproduciéndose desde finales del trescientos (1).

En efecto, los intercambios económicos, sustentados por sólidos fundamentos muy variados, se convirtieron en la salida natural de las aspiraciones comerciales valencianas, frustradas en otros mercados ocupados, desde antiguo, por los italianos, provenzales o por otras ciudades catalanas que se habían erigido en auténticas dominadoras de la mayor parte de las plazas mediterráneas. La región bañada por' is aguas del Estrecho de Gibraltar, entres Espanya y Barberia era el único rincón donde, a sus anchas, los traficantes locales desarrollaron todas sus posibilidades, explotando intensamente

(1) Rafael Arroyo: «El comercio valenciano de exportación con Italia y Berbería a finales del siglo XIV", VIII Congreso de Historia de la Corona de Aragón. Valencia, 1967 (1973), vol. III (parte II), pp. 255-289. Jacqueline Guiral: «Les relations commerciales du royaume de Valence avec la Berbérie au XV siècle», Mélanges de la Casa de Velázquez, 10 (1974), pp. 99-131. Hay traducción catalana en València, un mercat medieval. Edic.a cargo de Antoni Furió. Valencia, 1985, pp. 277-313. Rafael Cariñena y Andreu Díaz: «Corsaris valencians i esclaus barbarescs a les darreries del segle XIV: una subasta d'esclaus a València el 1385», Estudis Castellonencs, 2 (1984-85), pp. 439-456. 
los recursos de los que disponían (2). Independientemente de que tales negocios estuvieran mayoritariamente en manos cristianas o musulmanas, pero siempre asociados al núcleo comercial urbano, los intercambios se realizaron no exentos de riesgos graves que ponían, frecuentemente, en aprietos la continuidad de las relaciones. Si había un común denominador a los tráficos marítimos con Berbería ese era el de la inseguridad. Inseguridad, no tanto, motivada por la presencia de piratas berbericos, que interceptaban los comercios, como por la interferencia de los corsarios cristianos que, sabedores de lo lucrativo de las transacciones, gustarían de interceptar el rumbo de los barcos fletados en Valencia (3).

A la larga, sin embargo, el mayor problema vino derivado de otro factor enormemente delicado, conectado con la seguridad y la propia supervivencia de los tráficos. Si los piratas berberiscos, conocedores de las limitaciones de sus medios técnicos y humanos, no hostigaron, por regla general, las rutas de transporte de mercancías, si se lanzaron al asedio de las costas litorales valencianas. Este problema que ya era muy viejo a finales del cuatrocientos, se vio agudizado por la presión, cada vez más intensa, a la que se vieron sometidas las comunidades rurales de moros de la terra. En estas condiciones, el miedo a la finisecular invasión, que contribuyera a la reislamización del país y a la generación de un gran foco de inestabilidad peninsular, se hizo patente, agudizando las medidas represivas. Coincidía esa postura con un notable descenso de los intercambios en relación con Berbería. Este descenso no estuvo promovido por una coyuntura desfavorable, simplemente, sino que lo estuvo por una contracción general de los intercambios debido a la evolución estructural de la sociedad valenciana. Aunque la piratería, de todo género, intervino activamente en ese proceso, es probable que no se le pueda achacar el papel de motor esencial del repliegue económico valenciano de comienzos del XVI. La desviación del interés en sectores muy activos hacia campos de inversión o status sociales distintos de los comerciales, la desarticulación de grupos tan dinámicos como los musulmanes o los judíos, en unión de una intromisión, cada vez más efectiva, del aparato político de la monarquía, en los medios sociales, promoverá este retraimiento de la actividad económica tradicional (4).

Por lo que se refiere a la negociación con Berbería el signo de los nuevos tiempos vendrá determinado por el surgimiento de la Casa de Contratación de Orán y lo que ello implicaba desde el punto de vista de la filosofía de los negocios.

(2) Los jurados de Valencia repetirían, frecuentemente, como reclamación y lamento por actos piráticos cometidos contra la negociación de la ciudad, la circunscripción de los comercios locales a regiones muy restringidas del área del Estrecho o algún otro mercado aislado: Que aci, en aquesta ciutat la mercaderia és aterrada en major part, car la guerra de França e de la Anglaterra alcú no navega a Ponent e menys a Levant. Solament roman a nostres mercaders aquest rachó d'Espanya e vers Pisa, per florentins. Archivo Municipal de Valencia, Lletres Missives, g. ${ }^{3},-15$, f. 67668 r. Vid. Andrés Díaz: Problemas maritimos de Valencia a fines de la Edad Media: el corso, la pirateria y el cautiverio en su incidencia sobre la dinámica económica. 1400-1480, Valencia, 1988 (edic. microfichada), p. 546.

(3) Andrés Díaz: Problemas marítimos..., pp. 476-629.

(4) Ernest Belenguer: València en la crisi del segle XV. Barcelona, 1976. Jacqueline Guiral: "Convers a Valence en la fin du XV' siècle", Melanges de la Casa de Velázquez, 11 (1975), pp. 81-98. Mark D. Meyerson: «Tue war against Islam and the muslims at home: the mudejar predicament in the kingdom of Valencia during the reign of Fernando el Católico", Sharq al-Andalus, Estudios Árabes, 3 (1986), pp. 103-113. 


\section{La Casa de Contratación de Orán y Alfonso Sánchiz}

La formación de la Casa de Contratación de Orán es un acontecimiento que parece sorpredentemente desconocido, pese a representar un hito fundamental en la historia del comercio y de la vida marítima valenciana en relación con Berbería. Corresponde a Jacqueline Guiral el honor de haber dado a la luz pública la noticia de su existencia:

La conquista de las costas del litoral magrebí tendrá como consecuencia la recuperación del tráfico hacia Berbería que culmina en 1509-1510, en el momento en que el lugarteniente del tesorero del rey -el converso valenciano Alfonso Sánchiz- obtiene la concesión del monopolio comercial con África (5).

La noticia volverá a aparecer, nuevamente, en un trabajo de 1985:

Aquestes relacions es deterioraren a la fi del segle XV, en encetar-se una política sistemàtica de conquesta militar de les principals ciutats constaneres de l'Âfrica musulmana (1497-1510). Els models pacífics es veuen substituits per models agressius, els quals manquen al seu objectiu, ja que en voler fer-se amb el comerç de l'África del nord amb la instauració d'un monopoli d'Estat pel biaix de la Casa de Contractació d'Orà, trencaran l'equilibri que s'hi havia instaurat. D'aquí en avant el comerç amb l'Àfrica és a les mans del convers valencià Alfons Sanchiz. És la fí del règim del negoci individual que hem evocat. Hom pot preguntarse qui empeny aquesta politica que es revela econòmicament catastròfica ¿és novament una concepció senyorial que s'imposa a la concepció burguesa dels mercaders cristians o no cristians? (6).

Parece probable que con anterioridad a la elaboración de la tesis doctoral de Guiral la investigadora francesa desconocería la fuente. Al menos es significativa la carencia de indicaciones a este respecto en sus trabajos de la década de los setenta (7). De lo que no cabe duda es de que la transcendencia del acontecimiento es merecedor de una aproximación más profunda de la mera información que proporcionaba Guiral y que era desconocida con anterioridad (8).

(5) Jacqueline Guiral: Valencia, puerto mediterráneo en el siglo XV (1410-1525), Valencia, 1989, p. 45. Es la traducción de: Valence, port méditerranéen au XV siècle (1410-1525), Paris, 1986.

(6) Jacquline Guiral: «L'aportació de les comunitats jueva i musulmana al comerç marítim de València al segle XV», Afers, 5/6 (1987), pp. 33-46. Este artículo había sido publicado con anterioridad bajo el título de "L'apport des communautés juives et musulmanes. Au commerce maritime de Valence au XV siècle», Actes du $/ 1$ Colloque international d'Histoire, «Économies méditerranéennes: équilibres et inercommunications, $\mathrm{XIIl}{ }^{-} \mathrm{XI} \mathrm{X}^{\mathrm{c}}$ siècles. Centre de Recherches Néohelléniques. Fondation nationale de la recherche socientifique (Atenes, 1985), pp. 461-474

(7) La edición francesa del libro de Guiral es de 1986, pero en realidad éste es su tesis doctoral convenientemente adaptada, su tesis data de 1982. El artículo sobre las comunidades musulmana y judía está editado primeramente en 1985 con anterioridad en la bibliografía que hemos venido citando, vid. notas 1 y 4, nunca menciono el tema de la Casa de Contratación de Orán, que también era eludido por historiadores como Emilia Salvador: La economía valenciana en el siglo XVI (Comercio de importación), Valencia, 1972.

(8) Incluso en las referencias, menguadas, que da Guiral se aprecia un conocimiento muy relativo de la fuente. Asi, la cita que aparece en su libro sobre Valencia como puerto no se menciona el lugar de pro cedencia de la noticia. En el artículo del año 1985, traducido en 1987, se darán unas referencias muy aproximadas: ARV, Bailia, 1974, f. 441 en lugar de 440 y al 442 v y Bailía, 1167, f. 37 en lugar de $32 \mathrm{v}$ al $35 \mathrm{r}$, si nos referimos a las ordenaciones exclusivamente ó $30 \mathrm{r}$ al $35 \mathrm{v}$ si hacemos referencia a toda la documentación producida en 1516 y relativa a este tema. 
Alfonso Sánchiz procedía de una familia conversa relacionada con los negocios de los intercambios, que además estaba fuertemente ligada a la actividad real con la que colaboraba y se beneficiaba. De esta manera, se habría creado una verdadera simbiosis de intereses que permitió, sin dificultad, atribuir a Sánchiz, por parte de Fernando el Católico, la exclusiva de la administración de la Casa de Contratación oranesa (9).

Habíamos indicado con anterioridad que en la transición del cuatrocientos al quinientos los tráficos entre Valencia y Berbería se resistieron de una desaceleración del ritmo con el que venían desarrollándose. Guiral pudo constatar tal fenómeno, así como el traspaso de la iniciativa comercial a flotas italianas sin las cuales, quizás, los negocios no hubieran llegado a producirse (10). Como decíamos, semejante tendencia iba asociada a un incremento de la hostilidad naval por parte de ambos rivales, hasta el extremo de promover una auténtica campaña de ocupación de las plazas portuarias norte-africanas, desde las cuales fuera posible organizar flotas berberiscas que atacaran nuestras costas o lo que podía llegar a ser más grave: planear una invasión en toda la regla. La ocupación de las principales ciudades marítimas del África occidental producirá un cambio sustancial en la ya agonizante actividad mercante valenciano-berberisca. La densidad de barcos armados bajo bandera de la monarquía hispánica se acrecentaría extraordinariamente, más que nunca los mares del Estrecho y sus adyacentes se transformaron en aguas de guerra y los riesgos que ello comportaba para la navegación comercial crecieron en proporción directa. Así pues, la ocupación de las plazas norte-africanas conllevó, indefectiblemente, un cambio en el status tradicional de los intercambios y de las relaciones bilaterales, transformación que dejó caduca la vieja estructura de libre comercio, haciéndose necesario un nuevo diseño que interpretase la realidad de aquel momento más acorde con los tiempos. Efectivamente, para acabar con los fraudes y contrabandos, pero también con las presas ilegales, parecía conveniente centralizar todos los intercambios en manos de una sociedad, de una persona de la entera confianza del monarca, alguien como Sánchiz. Alfonso Sánchiz, quien por sus orígenes era un conocedor de la situación en Berbería, también estaba bien introducido en los círculos mercantes y, a la vez, asociado a la política del soberano. Desde luego, las intenciones de la realeza iban por el camino de organizar de forma más racional y fiscalizante esa actividad, que por realizarse con un país potencialmente enemigo peligroso, como Berbería, era necesario seguir muy de cerca. Al mismo tiempo, el soberano tenía como objetivo otro igualmente importante, el de penetrar decididamente en el mundo comercial, con la intención de fiscalizar e intentar controlar los resortes de la estructura de las transacciones. La filosofía que presidía esa trayectoria política se sustentaba tanto en la asunción de más y más papeles importantes en los aparatos sociales y burocráticos como en los económicos. Fernando el Católico, en unión de colaboradores leales como Sánchiz, aspirará a mucho más que sus antecesores, a la creación quasi del Estado. La fórmula empleada, sin embargo, como era de prever ado-

(9) Jacqueline Guiral: Valencia, puerto mediterráneo..., pp. 45-47, 130, 261, 272, 275, 208-9, 370, 375. $387,394,400,407,538-9$ y 565 .

(10) Jacqueline Guiral: «Les relacions comercials del regne de València amb Berberia al segle XV».., pp. 281-295. 
lecía de elementos incompatibles con aspiraciones sólo posibles después de las revoluciones burguesas. El mecanismo fiscalizador que podemos denominar Casa de Contratación de Orán no fue jamás una institución adecuada al estar concebida de acuerdo a normas tanto más arcaizantes cuanto más espíritu progresista pretendía aparentar, su modernidad basada en un monopolio señorializado solamente podía conducir al agotamiento de una de las rutas más tradicionales y rentables de los negocios valencianos.

\section{La constitución de la Casa de Contratación de Orán}

El primer documento al que hacemos referencia es una copia de la constitución de la Casa de Contratación de Orán que fue requerida en 1516, desde Granada, con motivo de un pleito mercantil (11). En 1516, las ordenaciones instauradas en Valladolid, el 15 de febrero de 1510, ya no estaban en vigor, aunque cabe la posibilidad de que se hubiese otorgado una prórroga de aquellas capitulaciones una vez que los plazos previstos caducaran (12). El escrito de 1510 consta de catorce puntos en los que se hace una detallada descripción de las competencias y características de la institución, de las responsabilidades reales y de las atribuciones del Tesorero Alfonso Sánchiz, comisionado por Fernando el Católico para ostentar la dirección de la nueva compañía que se configuraba.

La Casa de Contratación de Orán aparecía con objeto de ser el instrumento que canalizase y racionalizase los intercambios entre la península y Berbería. Su radio de acción abarcaría los reinos de Tremecén y Tenes (13). En estos territorios, ningún mercader podría efectuar transacciones libremente, siendo obligación del Capitán General de la plaza de Orán el auxilio a Sánchiz en el cumplimiento de esta norma (14). Cualquier comerciante estaba sujeto a acudir a Orán o Mazalquivir donde la compañía se encargaría de gestionar el negocio (15). De esta manera, desaparecía la posibilidad de efectuar transacciones comerciales directamente. Se instauraba una especie de monopolio privado en manos del tesorero real, aunque el soberano participara activamente a través de varias fórmulas. Efectivamente, si la empresa era la encargada de los intercambios, los almacenes y depósitos que se instalaran en Orán serían edificios de la monarquía, cedidos a Sánchiz con la condición de que éste debía de acondicionar y reparar los desperfectos que se produjeran (16). Por otro lado, pese a que el tesorero real era autorizado a contratar subordinados que atendiesen sus asuntos en Orán o en cualquier otro lugar, sería competencia del monarca designar a la persona que llevara los libros de entradas y salidas de mercancías (17). Por último, competía al monarca, igualmente, hacer pública la prohibición de comerciar con moros o judíos, atribución sólo reserva-

\footnotetext{
(11) Archivo del Reino de Valencia (ARV), Bailía, 1167, mano O, f. $30 \mathrm{r}$ al $32 \mathrm{r}$.

(12) Vid. nota 33.

(13) ARV, Bailia, 1167, mano O, f. 32 v. Capítulo I.

(14) Íbidem, t. 33 rv. Capítulo IV.

(15) Íbidem, f. 32 v. Capitulo I.

(16) Íbidem, f. $32 \vee 33$ r. Capitulo II.

(17) Ibidem, f. 33 v 34 r. Capítulo Vl.
} 
da a la Casa de Contratación, mediante los correspondientes pregones realizados en Orán (18) y garantizar la seguridad de los bienes que llegasen a esa plaza por medio de la expedición de los oportunos salvoconductos (19).

Al margen de estos acuerdos puntuales, en los que la intervención real y la de Alfonso Sánchiz iban de la mano, se efectuó una clara división de funciones entre las dos partes. Entre los privilegios de los que disfrutará Sánchiz figurarán el de poder comprar al contado y a plazos, sin límite, en las mercancías destinadas a Orán, o poder intervenir en la contratación de fletes y seguros mercantiles, que se efectuaran en los negocios realizados con moros y judíos (20). Esta libertad de acción contrastaba con la rigidez en la fijación de derechos que se cobrasen por la negociación. El tesorero vendría obligado a mantener las tasas fiscales existentes en época de la dominación musulmana en la ciudad (21). No obstante, los beneficios que se lograran serían repartidos al cincuenta por ciento entre el rey y Sánchiz, bien entendido que de la mitad correspondiente al valenciano un sexto iría a parar al tesorero Francisco de Vargas, previsiblemente, persona encargada por Fernando el Católico de fiscalizar las cuentas de la compañía (22). Precisamente, cuatro meses después de concluido cada año comercial se presentaria el balance correspondiente. Se establecía que en caso de que el resultado de la gestión fuera negativo pero restasen mercancias por vender en los almacenes de la Casa de Contratación, éstas deberían de ser vendidas para liquidar las cuentas (23). El volumen de las transacciones y la complejidad del funcionamiento de la compañía recomendarán la instalación de dos depósitos de reserva a este lado del mar: en Cartagena y Eivissa (24). Por último, también en sintonía con la idea de controlar una empresa de grandes dimensiones, se estipulará que Sánchiz pudiese disponer de guardas que vigilasen las puertas de acceso a Orán para impedir cualquier violación de las normas establecidas (25).

Por lo que se refiere a las competencias de la monarquía, ya hemos apuntado que suya era la mitad de las ganancias, que su responsabilidad consistía en pregonar la prohibición del libre cambio con Berbería o distribuir los salvoconductos para las mercancías que llegasen a Orán. Sabemos, así mismo, que la revisión de cuentas, aunque pagada por Sánchiz, dependía directamente del rey, así como los edificios donde se custodiaría la mercancía, por ejemplo. Se establecieron, igualmente, medidas de garantía para asegurar que si la milicia, costeada por el soberano en la plaza, saqueaba o dañaba las instalaciones de depósito de mercancías, en algún hipotético motín, fuera el mismo rey el que corriese con los gastos ocasionados (26). De igual forma, quedó establecido que si el monarca concedía licencias de comercio con Berbería,
(18) Íbidem, f. 35 r. Capítulo XII.
(19) Ibidem, f. 32 v 33 r. Capítulo 11.
(20) íbidem, f. 33 r. Capítulo III.
(21) ibidem, f. 33 v. Capitulo V.
(22) libidem, f. 34 r. Capítulo VII.
(23) Íbidem, f. 34 rv. Capítulo VIII.
(24) Íbidem, f. 35 r. Capitulo XIII.
(25) ibidem, f. 35 r. Capítulo XIV.
(26) Íbidem, f. 35 r. Capítulo XI. 
La Casa de Contratación de Orán y el área litoral bajo su influencia. 1510-1514

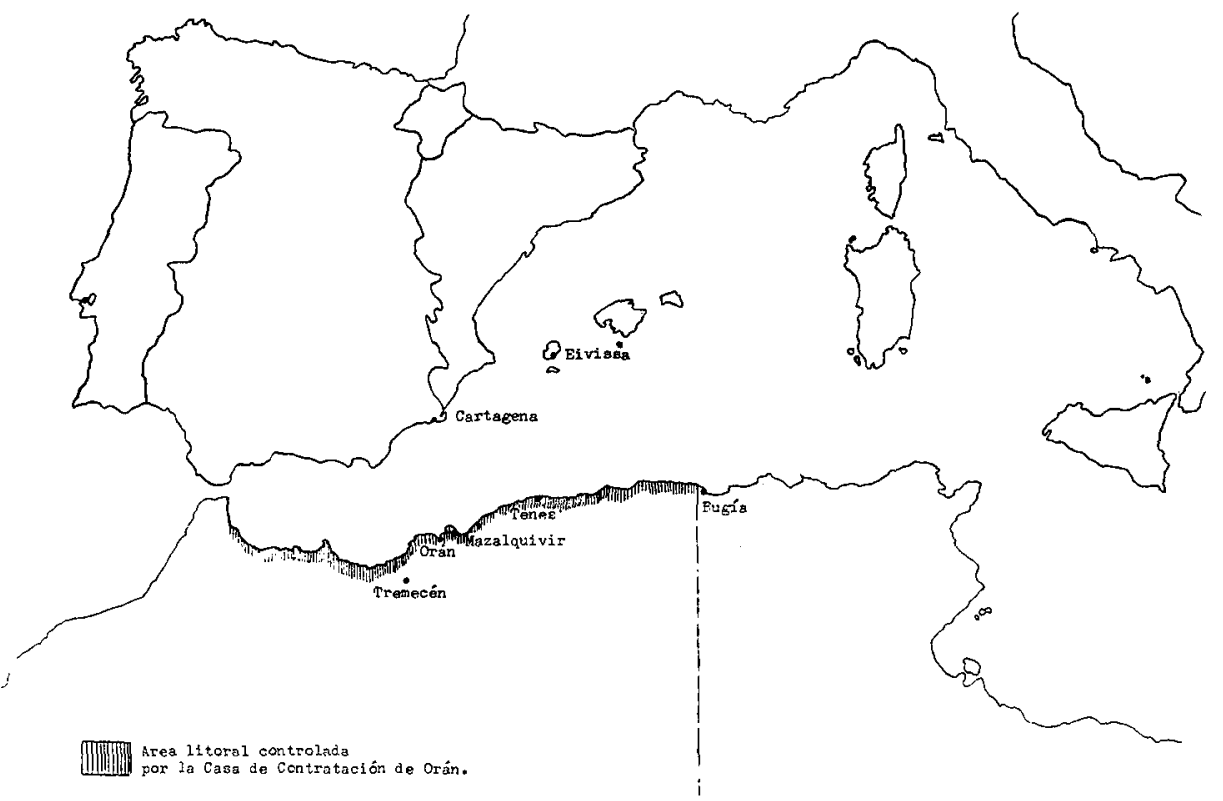

sin respetar el monopolio de Sanchiz, éste cobraría, en contrapartida, el valor de lo negociado, es decir, lo mismo que si se interceptase cualquier cargamento de contrabando.

Tenían estas ordenanzas su correspondiente cláusula de índole caritativa. Así, se autorizaba a los rectores de la compañía a distraer algunas sumas para dotar la fábrica de la iglesia de Orán, para redención de cautivos y otras obras misericordiosas (27). Pero, sobre todo, el acta de nacimiento de la Casa de Contratación de Orán tenía una disposición de disolución temporal. Ciertamente, la concesión del monopolio de explotación a Alfonso Sánchiz, que comenzaba en 1510 concluiría en 1514 indefectiblemente. Período de cuatro años que se prolongaría por todo 1515 para las mercancías del tesorero que no se hubiesen podido vender siempre y cuando no superarsen los 10 ó 12.000 ducados. Los beneficios de estas ventas serían repartidos conforme a lo pactado en el documento, sin embargo, si el monto de lo almacenado superaba los 12.000 ducados sería atribuido íntegramente al monarca (28).

\section{El previsible final del monopolio}

Estas orientaciones fueron dadas en Valladolid el 15 de enero de 1510 , sin embargo, tales capítulos no llegaron a Valencia como habían sido redacta-

(27) íbidem, f. 34 v. Capitulo IX.

(28) ibidem, f. 34 v. Capitulo $X$. 
das. En efecto, no será hasta el 5 de agosto de 1510 cuando Alfonso Sánchiz se presente ante el Baile General mostrando la provisión real correspondiente (29) Esta provisión, no obstante, no será la dada en Valladolid el 15 de enero sino una síntesis de aquella otorgada en Madrid a 13 de marzo (30). Este escrito, que es un resumen del anterior, elude algunos extremos que no fueron copiados, dando una visión incompleta de las características de la Casa de Contratación. Los catorce puntos del primer documento quedaban reducidos a cuatro en el segundo, haciéndose hincapié, esencialmente, en el establecimiento del monopolio, sus competencias y las obligaciones del monarca. Se obviaban, precisamente, dos extremos transcendentales, como el reparto de los beneficios entre el soberano y Sanchiz o la limitación de la existencia de la sociedad hasta 1514-15, entre otros (31). Fue por ello este documento y no las capitulaciones in extenso el que se haría público en Valencia el 8 de agosto de 1510 (32). Así pues, hay que suponer que la mayoría de la gente, incluyendo a los posibles mercaderes interesados en la contratación de bienes para Berbería, acabo teniendo una información sesgada de las caracteristicas del nuevo monopolio. La responsabilidad de la insuficiencia en la publicación de las normas establecidas habrá que atribuirlas, prioritariamente, a Sánchiz, el primer interesado en dar una visión parcial del asunto, pero también en los elementos del aparato real que expidieron el documento de marzo sin prever el mal uso que podría hacerse de él, y es precisamente por esas circunstancias por las que hemos podido, al final, acceder a la verdad del caso.

Decíamos que por un pleito mercantil de 1516 se requirió a Alfonso Sánchiz a que presentara las capitulaciones establecidas relativas a la Casa

(29) ARV, Bailia, 1164, f. 440 v 442 v.

(30) ibidem, f. 440 v 442 r.

(31) Primeramente, que ell dicho Alonso Sanchis tenga cargo de toda la contractación que se hoviere de fazer en la dicha ciutat de Horán e reynos de Tremizén e Tenez, e los que tovieren por ell cargo e no otra persona alguna, ansí en las cosas que se hovieren de vender a los moros e judios e a otras qualesquier personas hovieren de vender, e que otra persona no puede contractar con los susodichos sino, solamente, el dicho Alonso Sanchis o los que por él tuvieren cargo, con tanto que no pueda ser la dicha contractación sino por la dicha ciutat de Orán y no por otra parte ni partes.

Y otrosí, que su altesa manda publicar con pregón que nengua persona sea osada de contractar con los moros e otros qualesquier personas de los reynos de Tremizén e Tenez, sin lixencia, y esto mismo se pregone en la dicha ciudat de Orán.

E otrosí, que ell dicho tesorrero Alonso Sanchis y los que por ell tuvieren cargo de la dicha contractación puedan poner guardas a los puertos de la dicha ciudat de Orán, para que nadi pueda poner ni sacar mercaderías sin su cédula, porque no se haga fraude en la dicha contractación.

Otrosí, que su altesa mande al Capitán General, questá o stuviere en Orán, que de todo el favor e ayuda que fuere necessario al hazedor y a las otras personas que stuvieren con las dichas mercadurias en la dicha ciutat de Orán por ell dicho Thesorero Alonso Sanchis, y que ell dicho Capitán, ni otra persona, direste ni indireste, no trate ni consienta tractar ni negociar de mercadurias en la dicha ciutat de Orán y reynos de Tremizén e Tenez, azí en los que se ovieren de vender a los moros e judios e otros qualesquiere personas como en los que se hovieren de comprar dellos, y que los que contractaren contra la dicha prohibición pierdan todos los bienes e mercadurías que contractaren o el valor 441 vdellas como se contiene en las cartas de vedamiento de su alteza con tanto que los bienes dellos que contractaren, contra la dicha prohibición en la dicha ciudat de Orán o vila de Maçalquevir e su tierra, se appliquen a la dicha contractación. Y que su alteza promete de no dar lixencia a persona alguna para levar mercadurías a la dicha ciudat de Orán y reynos de Tremicén e Tenes, ni para saquar de allá durante el tienpo de la contractación, y si la diere que su alteza sea obligado pagar a esta companyía el interesse que las tales personas a quien dire lixencia ganares.

ARV, Bailía, 1164, f. $441 \mathrm{rv}$.

(32) Vid. nota 30. 
de Contratación (33). El pleito en cuestión se produjo cuando Joan de Santa $\mathrm{Fe}$ intentó sacar algunos bienes al margen del monopolio que controlaba la negociación, previsiblemente todavía en 1516. Aunque cabe la posibilidad, como quedó dicho, de que se renovara la vigencia de la compañía, también es posible que Sánchiz, escudándose en la carencia de información al respecto intentase, arbitrariamente, continuar con la empresa de manera ilícita, hasta que fuese descubierto por las indagaciones de este caso.

En definitiva, pues, la vida de la Casa de Contratación de Orán estaría sujeta a un anhelo de modernización de las estructuras políticas y económicas, en la época de Fernando el Católico, que no se correspondía con la realidad de las circunstancias históricas en las que se hallaba. La creación del monopolio no sirvió para impulsar la negociación con Berbería, que estaba decayendo indefectiblemente (34). Sirvió, en todo caso, como recompensa a uno de los servidores de la política de la monarquía que intentó, a su costa, beneficiarse, incluso tal vez de manera ilegal, de la situación, dentro de unas concepciones que tenían muy poco de filosofía modernizadora aparentemente instaurada. Por el contrario, podía enmarcarse perfectamente dentro de los métodos clásicos de los privilegiados para detentar el poder y su preeminencia social.

\section{(33) Vid. nota 12}

(34) Según Guiral, el número de barcos con destino a Berbería sería, por años: 1503: 9; 1507: 3; 1529: 27; 1510: 28; 1519: $1 ; 1520: 6 ; 1522: 7$. Vid. Jacqueline Guiral: Valencia, puerto mediterráneo.., p. 46. Para una moderna aproximación al período de los Reyes Católicos y su política general puede ser interesante la consulta de una síntesis monográfica como la de J.N. Hillgarth: Los Reyes Católicos. 1476-1516, Barcelona, 1984. 